\title{
Gastric Tubulovillous Adenoma
}

National Cancer Institute

\section{Source}

National Cancer Institute. Gastric Tubulovillous Adenoma. NCI Thesaurus. Code C7037.

An intestinal-type adenomatous polyp that arises from the stomach. It is characterized by the presence of a tubulovillous architectural pattern. 